\title{
Bioinformatics prediction and analysis of hub genes and pathways of three types of gynecological cancer
}

\author{
YANYAN LIU ${ }^{1}$, YUEXIONG YI ${ }^{1}$, WANRONG WU ${ }^{2}$, KEJIA WU ${ }^{1}$ and WEI ZHANG ${ }^{1}$ \\ ${ }^{1}$ Department of Gynecology, Zhongnan Hospital of Wuhan University, Wuhan, Hubei 430071; \\ ${ }^{2}$ The First Department of Gynecology, Renmin Hospital of Wuhan University, Wuchang, Wuhan, Hubei 430060, P.R. China
}

Received May 8, 2018; Accepted April 15, 2019

DOI: $10.3892 / \mathrm{ol} .2019 .10371$

\begin{abstract}
Cervical, endometrial and vulvar cancer are three common types of gynecological tumor that threaten the health of females worldwide. Since their underlying mechanisms and associations remain unclear, a comprehensive and systematic bioinformatics analysis is required. The present study downloaded GSE63678 from the GEO database and then performed functional enrichment analyses, including gene ontology and pathway analysis. To further investigate the molecular mechanisms underlying the three types of gynecological cancer, protein-protein interaction (PPI) analysis was performed. A biological network was generated with the guidance of the Kyoto Encyclopedia of Genes and Genomes database and was presented in Cytoscape. A total of 1,219 DEGs were identified for the three types of cancer, and 25 hub genes were revealed. Pathway analysis and the PPI network indicated that four main types of pathway participate in the mechanism of gynecological cancer, including viral infections and cancer formation, tumorigenesis and development, signal transduction, and endocrinology and metabolism. A preliminary gynecological cancer biological network was constructed. Notably, following all analysis, the phosphoinositide 3-kinase (PI3K)/Akt pathway was identified as a potential biomarker pathway. Seven pivotal hub genes (CCNA2, CDK1, CCND1, FGF2, IGF1, BCL2 and VEGFA) of the three gynecological cancer types were proposed. The seven hub genes may serve as targets in gynecological cancer for prevention and early intervention. The PI3K/Akt pathway was identified as a critical biomarker of the three types of gynecological cancer, which may serve a role in the pathogenesis. In summary, the present study provided evidence that could support the treatment of gynecologic tumors in the future.
\end{abstract}

Correspondence to: Professor Wei Zhang, Department of Gynecology, Zhongnan Hospital of Wuhan University, 169 South of Donghu Road, Wuchang, Wuhan, Hubei 430071, P.R. China E-mail: zw6676@163.com

Key words: cervical cancer, endometrial carcinoma, vulvar carcinoma, bioinformatics, phosphoinositide 3-kinase/Akt

\section{Introduction}

A gynecological tumor is a type of malignant tumor that occurs in the female reproductive system and seriously threatens the life of the patient. Among the types of gynecological tumor, cervical cancer (CC), endometrial carcinoma (EC) and vulvar carcinoma (VC) are the top three most common tumors of the female genital system, besides ovarian cancer (1). Despite an overall decline in the incidence and mortality rates due to increased understanding of the disease, gynecological cancer remains a significant health care burden worldwide (1). Early detection and treatment are essential for improving patient outcomes; however, these require improved understanding of the molecular pathology of the disease, in addition to identification of appropriate biomarkers and drug targets. Previous studies have demonstrated that the occurrence of CC is closely associated with human papillomavirus (HPV) infection (2-4). VC can be separated into two types, including one type that more frequently occurs in young females. This type involves the progression of a vulvar intraepithelial neoplasia caused by HPV infection, particularly HPV 16 and 18 (5). Based on pathogenetic perspectives, EC is also classified into two groups according to estrogen dependence (6). Although there have been a number of previous etiology studies, the exact pathogenesis of these three types of cancer remains unclear.

There are certain pathological and etiological associations between $\mathrm{CC}$ and $\mathrm{VC}$, as both are squamous cell cancers and both are associated with HPV infection $(2,5)$. Unlike CC and $\mathrm{VC}, \mathrm{EC}$ is associated with sex hormones, which is similar to common invasive tumors in females, including breast and ovarian cancer (6). In addition, clinical diagnoses of these three cancer types rely predominantly on pathology (7). Precise biomarkers in early stages of $\mathrm{CC}, \mathrm{EC}$ and $\mathrm{VC}$ remain unknown.

It is understood that cervical, endometrial and vulvar tissues all originate from the same embryological origin, the paramesonephric ducts, which give rise to the whole female reproductive tract and develop into different organs, following complex regulatory process (8). For this reason, although there a number of differences between $\mathrm{CC}, \mathrm{EC}$ and $\mathrm{VC}$, it has been hypothesized that these three types of gynecological tumor share a similar mechanism and certain specific marker molecules may be common to their tumorigenesis 
and development. Therefore, a comprehensive analysis may improve understanding of these three types of tumor.

Advancements in biotechnology have improved the availability of high-throughput data, including genomic, proteomic and metabolomics data, which supports in-depth scientific research. High-throughput data can assist with effective early diagnosis, prognosis prediction and investigations of molecular mechanisms for numerous types of disease. The present study used GSE63678 microarray data downloaded from the Gene Expression Omnibus (GEO) to determine the differentially expressed genes (DEGs, which were identified between cancerous samples and non-cancerous samples) of CC, EC and VC (9). Subsequently, functional enrichment analyses were performed, including gene ontology (GO) and pathway analysis, and a protein-protein interaction (PPI) network was generated to identify the significant biological terms associated with the DEGs. The genes that were screened out by the PPI network were considered as the hub genes, which may serve important roles in the mechanism of CC, EC and VC. In addition, a gene-pathway network was constructed and further analysis was performed. The complete flowchart of the present study is presented in Fig. 1. In summary, the current study may provide a new perspective for elucidating the biological significance of three types of gynecological cancer, and assist with the identification of potential candidate biomarkers for diagnosis, prognosis and therapy.

\section{Materials and methods}

Microarray data. The gene expression profile GSE63678 on the platform of the GPL571 Affymetrix Human Genome U133A 2.0 Array was downloaded from the GEO database (http://www.ncbi.nlm.nih.gov/geo/). GSE63678 is a dataset submitted by Pappa et al (9), containing 18 cancer samples, including five cervical, seven endometrial and six vulvar samples, and 17 normal samples, including, five cervical, five endometrial and seven vulvar samples.

Identification of DEGs. GEO2R (http://www.ncbi.nlm.nih. gov/geo/geo2r) is an interactive network analysis tool of the GEO database based on $\mathrm{R}$, in which two sets of samples can be compared under the same experimental conditions (10). Associated gene data were divided into CC, EC and VC groups. Subsequently, the GEO2R (10) tool and limma package (11) available through Bioconductor (version 3.8) of R Studio (version 3.5) were used to compare the gene expression of the $\mathrm{CC}, \mathrm{EC}$ and VC groups. $\mathrm{P}<0.05$ and a fold-change $>2$ were considered to indicate a DEG. The distribution of the DEGs in the three tumor types was presented as a Venn diagram using FunRich software (version 3.0) (12).

Construction of the PPI network and identification of hub genes. Search Tool for the Retrieval of Interacting Genes (http://string-db.org/; version 10.5) is a software system that is commonly used to search for known proteins and predict interactions (13). The experimentally validated interactions with a combined score $>0.7$ were selected as significant and DEGs with a connection number $<2$ were removed. The PPI network was visualized using Cytoscape (https://cytoscape. org/; version 3.6.0). The nodes with degree, closeness and betweenness scores higher than the mean, as calculated by the Cytoscape plugin Centiscape, were considered hub nodes.

GO analysis of the hub genes. WEB-based Gene SeT AnaLysis Toolkit (http://www.webgestalt.org/; revision 2017) is a popular software tool for functional enrichment analysis, which covers seven biological contexts, including GO (14). Therefore, this software was used in the present study for GO enrichment analysis. The false discovery rate (FDR) was set at $<0.05$ to conduct the GO analysis of the DEGs.

Pathway enrichment analysis of the hub genes. The hub genes were uploaded to ToppGene (https://toppgene.cchmc. org/,) for pathway enrichment analysis. The two frequently used databases, Kyoto Encyclopedia of Gene and Genomes (KEGG; www.genome.jp/kegg) and Biocarta (www.biocarta. com), were used to perform this analysis (15). The FDR was set at $<0.05$.

Pathway crosstalk analysis. The enriched pathways were recruited for further crosstalk analysis to investigate the associations between them. As described previously (15), to measure the association between two pathways, Jaccard coefficient $(\mathrm{JC})=\mathrm{A} \cap \mathrm{B} / \mathrm{A} \cup \mathrm{B}$ and overlap coefficient $(\mathrm{OC})=\mathrm{A} \cap \mathrm{B} / \mathrm{min}(|\mathrm{A}|,|\mathrm{B}|)$ were adopted, where $\mathrm{A}$ and $\mathrm{B}$ are the gene items contained in the two pathways, $\min$ is the minimum, $\cap$ is the intersection of $\mathrm{A}$ and $\mathrm{B}$, and $\mathrm{U}$ is the union of $\mathrm{A}$ and $\mathrm{B}$. Since limited biological information was available, pathways containing $<3$ genes were excluded. Similarly, the pathway pairs with $<2$ overlapping genes were removed. Subsequently, the pathway network was presented with Cytoscape according to the JC and OC value of each selected pair (16), and the MCODE plug-in (17) (version 1.4.2; apps.cytoscape.org/apps/MCODE) for Cytoscape was used to find clusters and highly interconnected regions in any network was used to analyze the clusters.

Gene-pathway network analysis. To further investigate the developmental mechanisms of CC, EC and VC, the hub genes were mapped into a crosstalk network. By analyzing the interactions between the genes and pathways with KEGG and Biocarta, the connected nodes were linked with arrows. The gene-pathway network was constructed and visualized in Cytoscape. The degree was calculated and nodes with a degree greater than the mean degree of all nodes were selected to constitute a sub network.

\section{Results}

Identification of DEGs. Following screening with the criteria of $\mathrm{P}<0.05$ and fold-change $>2$, a total of 1,219 DEGs were identified. In the CC group 138 DEGs were revealed, including 87 upregulated genes. In addition, 479 DEGs were identified in the EC group, including 272 upregulated genes. Finally, 734 DEGs, including 172 upregulated genes, were revealed in the VC group. As demonstrated in Fig. 2A, 84, 378 and 630 DEGs were exclusively identified in $\mathrm{CC}, \mathrm{EC}$ and $\mathrm{VC}$ groups, respectively. However, 23 DEGs were present in both the CC and EC group, 73 DEGs were identified in both the EC and VC groups, and 26 DEGs were revealed in both the CC and VC groups. Furthermore, five mutual genes, including signal sequence 


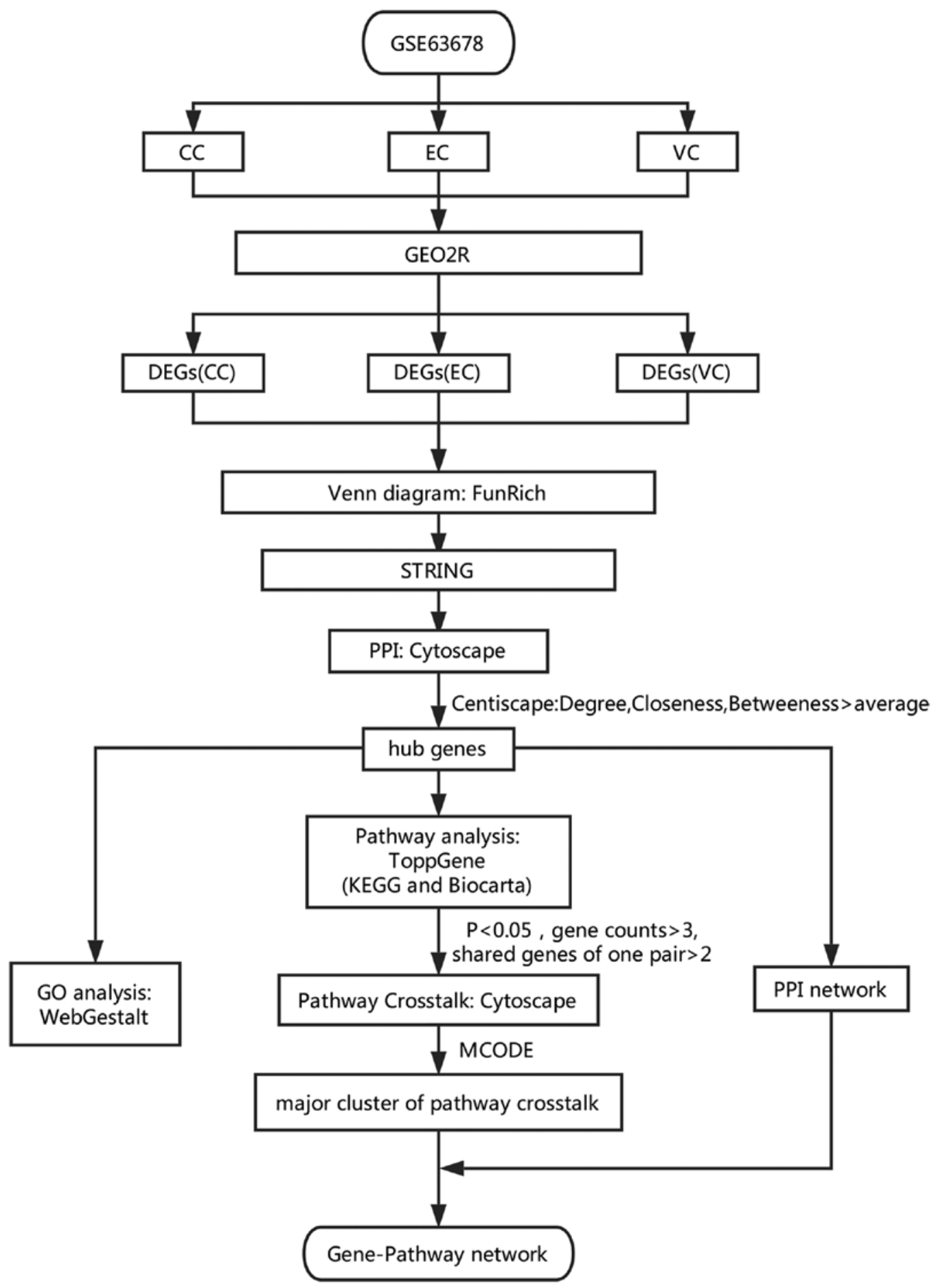

Figure 1. Flowchart of the study. CC, cervical cancer; EC, endometrial cancer; VC, vulvar cancer, PPI, protein-protein interaction.

receptor subunit 1 (SSR1), flap structure-specific endonuclease 1 (FEN1), cyclin A2 (CCNA2), signal transducer and activator of transcription 1 (STAT1) and C-X-C motif chemokine ligand 12 (CXCL12), were identified in all three groups.

Hub genes and PPI network. Following calculation by Centiscape, the mean values of degree, closeness and betweenness were $12.64080,3.73 \times 10^{-4}$ and 2081.81034 , respectively. Additionally, 25 hub genes were identified, including six downregulated genes and 19 upregulated genes (Table I). Three histone cluster family members were revealed as hub genes, including histone H2B type 1-H (HIST1H2BH), histone cluster $1 \mathrm{H} 2 \mathrm{~B}$ family member D (HIST1H2BD) and histone cluster 1 H2B family member K (HIST1H2BK), and the five hub genes were cell cycle regulatory proteins, including CCNA2, cyclin B1 (CCNB1), cyclin D1 (CCND1), aurora kinase A (AURKA) and cell division cycle 20 (CDC20). Furthermore certain genes associated with tumor progression were identified, including vascular endothelial growth factor A (VEGFA), FYN proto-oncogene, Src family tyrosine kinase (FYN), baculoviral IAP repeat containing 5 (BIRC5) and the apoptosis regulator B-cell lymphoma 2 (BCL2). 
A

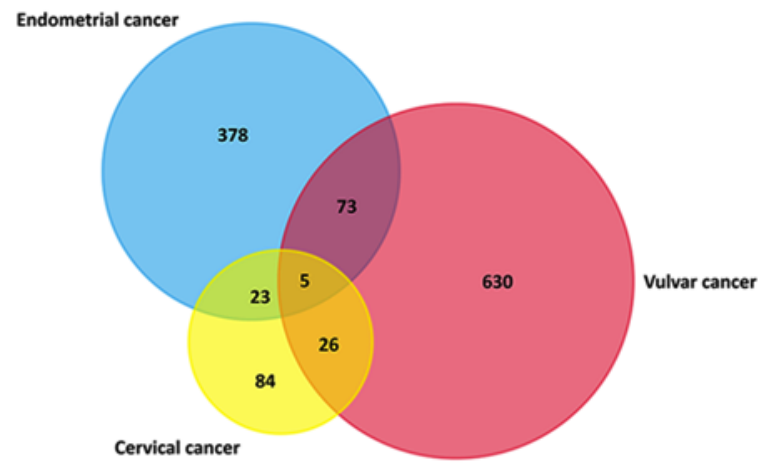

B

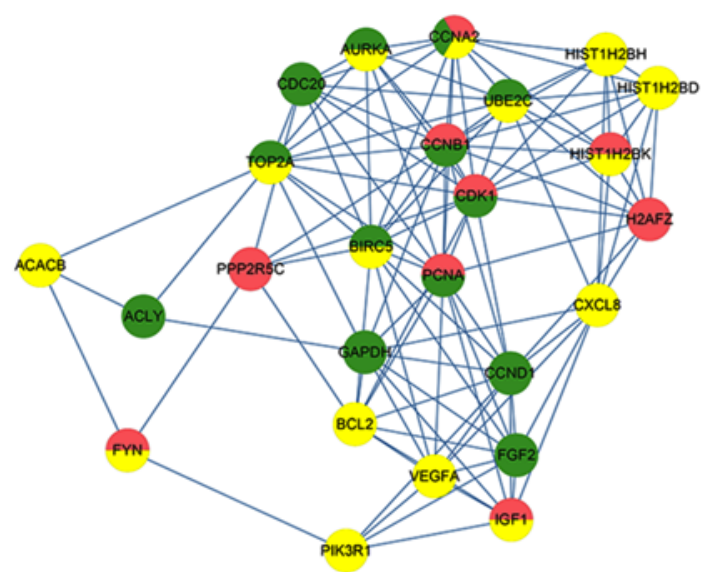

C

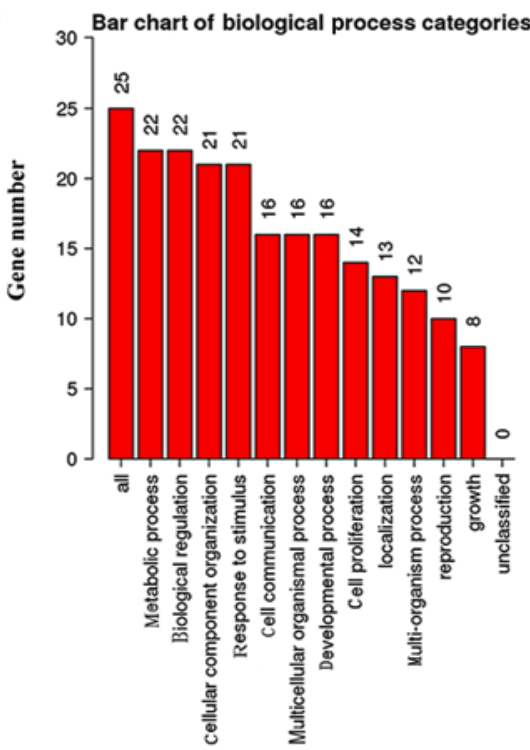

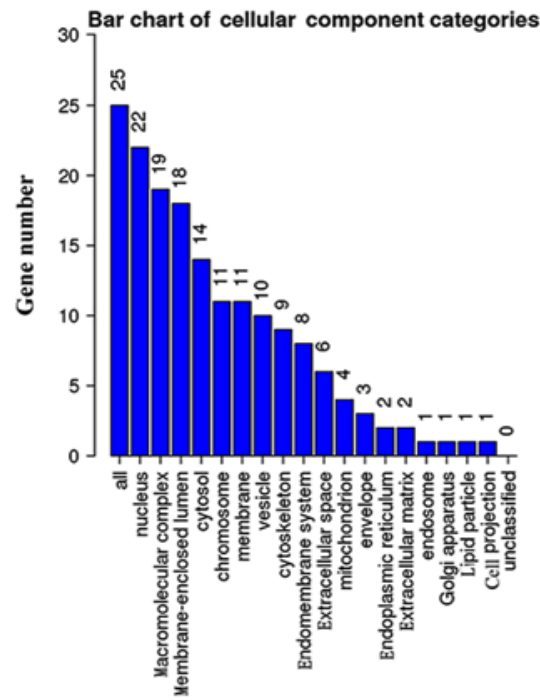

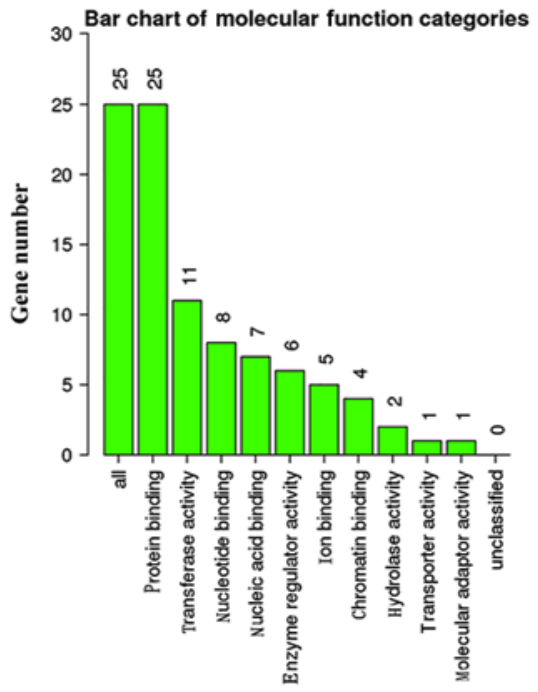

Figure 2. DEGs in CC, EC and VC. (A) Venn diagram of three gynecological tumor types. The yellow circles represent the DEGs in CC, the blue circles represent the DEGs in EC and the red circles represent the DEGs in VC. The overlapping areas indicate the shared genes of any two or three groups. (B) The protein-protein interaction network of the 25 hub genes. The circle nodes represent genes. Red indicates genes in CC, yellow represents genes in EC and green indicates genes in VC. The thickness of the line between any two nodes represents the strength of the connection. (C) Gene ontology analysis of 25 DEGs. The results are presented for the following three categories: Biological process, cellular component and molecular function DEG, differentially expressed gene; $\mathrm{CC}$, cervical cancer; EC, endometrial cancer; VC, vulvar cancer.

The PPI network of the 25 hub genes with 25 nodes and 114 edges is presented in Fig. 2B. The top five genes with the highest degrees were CDK1, CCNB1, CDC20, CCNA2 and AURKA. All five of these genes are associated with cell cycle regulation, which indicates that cell cycle dysfunction serves an important role in the development of gynecological tumors.

GO enrichment analysis. A total of 25 DEGs were used to perform GO enrichment analysis (Fig. 2C). For cellular component terms, 22 out of the 25 genes were revealed to be located in the 'nucleus' and approximately $80 \%$ were identified to participate in the 'macromolecular complex' (19 genes) and 'membrane-enclosed lumen' (18 genes). In the biological process category, the DEGs were associated with 'biological regulation' (22 genes), 'metabolic process' (22 genes), 'cellular component organization' (21 genes) and 'response to stimulus' (21 genes). In the molecular function category all 25 DEGs were associated with 'protein binding' ( 25 genes).
Pathway enrichment analysis of the hub genes. By uploading the 25 genes into ToppGene, 86 significant pathways were identified. The biological processes involved in these pathways can be divided into the following five main categories: i) viral infections and cancer formation, including 'viral carcinogenesis' and 'hepatitis B', ii) tumorigenesis and development, including 'colorectal cancer' and 'proteoglycans in cancer', iii) signal transduction, including 'PI3K-Akt signaling pathway' and 'AMPK signaling pathway', iv) endocrinology and metabolism, including 'AGE-RAGE signaling pathway in diabetic complications' and 'endocrine resistance', and v) others, including 'genes encoding secreted soluble factors' and 'NFAT and hypertrophy of the heart (transcription in the broken heart)'. In addition, 19 pathways were identified to be downregulated and 17 pathways were revealed to be upregulated (Table II).

Pathway crosstalk analysis. To further investigate how the identified pathways interact with each other, a pathway 
Table I. Topological parameters of the hub genes.

\begin{tabular}{|c|c|c|c|c|c|}
\hline Gene & Degree & Betweeness & Closeness & Group & Regulation \\
\hline Mean & 13 & 2081.81034 & $3.73 \times 10^{-4}$ & - & - \\
\hline CDK1 & 115 & 20448.4838 & $5.21 \times 10^{-4}$ & $\mathrm{CC} / \mathrm{EC}$ & Up \\
\hline CCNB1 & 100 & 16335.9142 & $5.23 \times 10^{-4}$ & $\mathrm{CC} / \mathrm{EC}$ & Up \\
\hline CDC20 & 92 & 8148.54809 & $4.76 \times 10^{-4}$ & $\mathrm{EC}$ & Up \\
\hline CCNA2 & 91 & 8126.90458 & $4.89 \times 10^{-4}$ & $\mathrm{CC} / \mathrm{EC} / \mathrm{VC}$ & $\mathrm{Up}$ \\
\hline AURKA & 90 & 9181.94344 & $4.76 \times 10^{-4}$ & $\mathrm{EC} / \mathrm{VC}$ & $\mathrm{Up}$ \\
\hline TOP2A & 87 & 21409.6376 & $5.15 \times 10^{-4}$ & $\mathrm{EC} / \mathrm{VC}$ & Up \\
\hline UBE2C & 82 & 14916.6491 & $4.82 \times 10^{-4}$ & $\mathrm{EC} / \mathrm{VC}$ & Up \\
\hline BIRC5 & 80 & 16279.0157 & $5.13 \times 10^{-4}$ & $\mathrm{EC} / \mathrm{VC}$ & Up \\
\hline PCNA & 62 & 26080.2036 & $5.25 \times 10^{-4}$ & $\mathrm{CC} / \mathrm{EC}$ & Up \\
\hline VEGFA & 56 & 32712.0335 & $5.43 \times 10^{-4}$ & VC & Up \\
\hline PIK3R1 & 46 & 24576.8505 & $4.91 \times 10^{-4}$ & $\mathrm{VC}$ & Down \\
\hline HIST1H2BK & 43 & 8689.20717 & $4.70 \times 10^{-4}$ & $\mathrm{CC} / \mathrm{VC}$ & $\mathrm{Up}$ \\
\hline HIST1H2BD & 43 & 8689.20717 & $4.70 \times 10^{-4}$ & $\mathrm{VC}$ & $\mathrm{Up}$ \\
\hline HIST1H2BH & 42 & 8291.98846 & $4.70 \times 10^{-4}$ & $\mathrm{VC}$ & Up \\
\hline $\mathrm{ACACB}$ & 41 & 40853.547 & $4.98 \times 10^{-4}$ & $\mathrm{VC}$ & Down \\
\hline CXCL8 & 40 & 28927.396 & $5.16 \times 10^{-4}$ & $\mathrm{VC}$ & Up \\
\hline H2AFZ & 39 & 8793.56814 & $4.67 \times 10^{-4}$ & $\mathrm{CC}$ & $\mathrm{Up}$ \\
\hline IGF1 & 38 & 16278.2011 & $5.07 \times 10^{-4}$ & $\mathrm{CC} / \mathrm{VC}$ & Down \\
\hline ACLY & 37 & 34157.4527 & $4.81 \times 10^{-4}$ & $\mathrm{EC}$ & Up \\
\hline CCND1 & 36 & 28548.907 & $5.39 \times 10^{-4}$ & $\mathrm{EC}$ & Up \\
\hline GAPDH & 33 & 41598.1258 & $5.39 \times 10^{-4}$ & $\mathrm{EC}$ & Up \\
\hline PPP2R5C & 32 & 10238.8057 & $4.75 \times 10^{-4}$ & $\mathrm{CC}$ & UP \\
\hline FYN & 32 & 17254.3572 & $5.22 \times 10^{-4}$ & $\mathrm{CC} / \mathrm{VC}$ & Down \\
\hline FGF2 & 32 & 19465.3169 & $5.20 \times 10^{-4}$ & $\mathrm{EC}$ & Down \\
\hline BCL2 & 32 & 17923.6004 & $4.86 \times 10^{-4}$ & $\mathrm{VC}$ & Down \\
\hline
\end{tabular}

$\mathrm{CC}$, cervical cancer; EC, endometrial cancer; VC, vulvar cancer.

crosstalk analysis was conducted among the pathways that met the criteria. The approach was based on the assumption that two pathways can be considered to be associated if they share a proportion of genes (18). A total of 45 pathways contained more than two hub genes, of which 41 pathways met the criterion for crosstalk analysis.

The network of crosstalk, which includes these 41 pathways, is presented in Fig. 3A. The thickness of edge connecting two nodes represents the strength of the association between them, which was measured by the mean value of $\mathrm{OC}$ and JC. Using MCODE, two major clusters were identified from the whole network. The simple cluster involves three pathways associated with cell cycle, including 'Cell cycle', 'Oocyte meiosis' and 'Cyclins and Cell Cycle Regulation'. The complicated cluster containing a total of 32 nodes and 376 edges is presented in Fig. 3B. The five aforementioned types of pathways were interconnected to form the complex network, which indicates the complexity of the pathogenesis of $\mathrm{CC}, \mathrm{EC}$ and $\mathrm{VC}$.

Gene-pathway network construction of DEGs. By mapping the hub genes into the complicated sub-network according to the KEGG and Biocarta databases, a potential gene-pathway network was constructed to verify the associations between the candidate pathways and genes (Fig. 4). This network included 37 important pathways and 18 hub genes, including CCND1 presented in the middle with direct or indirect associations with all other genes. As the only overlapping gene of all three groups, CCNA2 possessed complicated connections with 'viral carcinogenesis', 'hepatitis B', 'cell cycle' and six other pathways. In addition, insulin-like growth factor-1 (IGF1), fibroblast growth factor 2 (FGF2) and CCND1 were located close to the middle of the gene-pathway network.

Sub gene-pathway network of DEGs. To screen the key factors, including genes and pathways, in the gene-pathway network, the degrees of all of nodes were calculated and nodes with a degree greater than the mean degree of all nodes were selected (Fig. 5). Seven genes (CCNA2, CDK1, CCND1, BCL2, IGF1, FGF2 and VEGFA) and six pathways ('Viral carcinogenesis', 'Hepatitis B', 'Focal adhesion', 'Pathways in cancer', 'PI3K-Akt signaling pathway' and 'Proteoglycans in cancer') were selected. Since these gene and pathways had more connections with other nodes, they were considered to more likely serve a role in CC, EC and VS. 
Table II. Pathways enriched in three types of gynecological cancer.

\begin{tabular}{|c|c|c|c|}
\hline Pathway & Regulation & P-value & Genes in the pathway \\
\hline Viral carcinogenesis & - & $3.43 \times 10^{-9}$ & $\begin{array}{l}\text { HIST1H2BD, CCND1, CDK1, HIST1H2BH, } \\
\text { CDC20, PIK3R1, HIST1H2BK, CCNA2 }\end{array}$ \\
\hline Hepatitis B & - & $9.66 \times 10^{-9}$ & $\begin{array}{l}\text { BIRC5, CCND1, BCL2, PIK3R1, PCNA, } \\
\text { CXCL8, CCNA2 }\end{array}$ \\
\hline AMPK signaling pathway & - & $1.13 \times 10^{-7}$ & $\begin{array}{l}\text { CCND1, PPP2R5C, IGF1, ACACB, } \\
\text { PIK3R1, CCNA2 }\end{array}$ \\
\hline Oocyte meiosis & - & $1.31 \times 10^{-7}$ & $\begin{array}{l}\text { AURKA, PPP2R5C, IGF1, CDK1, CDC } 20 \text {, } \\
\text { CCNB1 }\end{array}$ \\
\hline Cell cycle & Up & $1.31 \times 10^{-7}$ & $\begin{array}{l}\text { CCND1, CDK1, CDC20, PCNA, CCNA2, } \\
\text { CCNB1 }\end{array}$ \\
\hline EGFR tyrosine kinase inhibitor resistance & - & $4.35 \times 10^{-7}$ & FGF2, BCL2, IGF1, PIK3R1, VEGFA \\
\hline Pathways in cancer & - & $6.44 \times 10^{-7}$ & $\begin{array}{l}\text { FGF2, BIRC5, CCND1, BCL2, IGF1, } \\
\text { PIK3R1, CXCL8, VEGFA }\end{array}$ \\
\hline Progesterone-mediated oocyte maturation & - & $1.15 \times 10^{-6}$ & IGF1, CDK1, PIK3R1, CCNA2, CCNB1 \\
\hline AGE-RAGE signaling pathway in diabetic complications & - & $1.35 \times 10^{-6}$ & CCND1, BCL2, PIK3R1, CXCL8, VEGFA \\
\hline HIF-1 signaling pathway & - & $1.49 \times 10^{-6}$ & BCL2, IGF1, GAPDH, PIK3R1, VEGFA \\
\hline Focal adhesion & - & $2.13 \times 10^{-6}$ & $\begin{array}{l}\text { CCND1, BCL2, IGF1, FYN, PIK3R1, } \\
\text { VEGFA }\end{array}$ \\
\hline PI3K-Akt signaling pathway & - & $3.48 \times 10^{-6}$ & $\begin{array}{l}\text { FGF2, CCND1, BCL2, PPP2R5C, IGF1, } \\
\text { PIK3R1, VEGFA }\end{array}$ \\
\hline p53 Signaling Pathway & - & $3.94 \times 10^{-6}$ & CCND1, BCL2, PCNA \\
\hline IL-7 Signal Transduction & Down & $4.77 \times 10^{-6}$ & BCL2, FYN, PIK3R1 \\
\hline Colorectal cancer & - & $5.72 \times 10^{-6}$ & BIRC5, CCND1, BCL2, PIK3R1 \\
\hline p53 signaling pathway & - & $1.00 \times 10^{-5}$ & CCND1, IGF1, CDK1, CCNB1 \\
\hline Melanoma & - & $1.00 \times 10^{-5}$ & FGF2, CCND1, IGF1, PIK3R1 \\
\hline Cyclins and Cell Cycle Regulation & Up & $1.23 \times 10^{-5}$ & CCND1, CDK1, CCNB1 \\
\hline Platinum drug resistance & - & $1.25 \times 10^{-5}$ & BIRC5, BCL2, PIK3R1, TOP2A \\
\hline Regulation of BAD phosphorylation & Down & $1.80 \times 10^{-5}$ & BCL2, IGF1, PIK3R1 \\
\hline Prostate cancer & - & $2.52 \times 10^{-5}$ & CCND1, BCL2, IGF1, PIK3R1 \\
\hline Endocrine resistance & - & $3.71 \times 10^{-5}$ & CCND1, BCL2, IGF1, PIK3R1 \\
\hline Proteoglycans in cancer & - & $4.47 \times 10^{-5}$ & FGF2, CCND1, IGF1, PIK3R1, VEGFA \\
\hline Bladder cancer & Up & $7.25 \times 10^{-5}$ & CCND1, CXCL8, VEGFA \\
\hline Sphingolipid signaling pathway & - & $8.32 \times 10^{-5}$ & BCL2, PPP2R5C, FYN, PIK3R1 \\
\hline FoxO signaling pathway & - & $1.29 \times 10^{-4}$ & CCND1, IGF1, PIK3R1, CCNB1 \\
\hline Systemic lupus erythematosus & Up & $1.32 \times 10^{-4}$ & $\begin{array}{l}\text { H2AFZ, HIST1H2BD, HIST1H2BH, } \\
\text { HIST1H2BK }\end{array}$ \\
\hline $\begin{array}{l}\text { NFAT and Hypertrophy of the heart } \\
\text { (Transcription in the broken heart) }\end{array}$ & Down & $1.66 \times 10^{-4}$ & FGF2, IGF1, PIK3R1 \\
\hline Breast cancer & - & $1.80 \times 10^{-4}$ & FGF2, CCND1, IGF1, PIK3R1 \\
\hline Activation of Src by Protein-tyrosine phosphatase alpha & Up & $2.11 \times 10^{-4}$ & CDK1, CCNB1 \\
\hline Sonic Hedgehog (SHH) Receptor Ptc1 Regulates cell cycle & $\mathrm{Up}$ & $2.11 \times 10^{-4}$ & CDK1, CCNB1 \\
\hline AKAP95 role in mitosis and chromosome dynamics & Up & $2.52 \times 10^{-4}$ & CDK1, CCNB1 \\
\hline Glioma & - & $2.75 \times 10^{-4}$ & CCND1, IGF1, PIK3R1 \\
\hline Pancreatic cancer & - & $2.75 \times 10^{-4}$ & CCND1, PIK3R1, VEGFA \\
\hline $\begin{array}{l}\text { Expression of cyclins regulates progression through } \\
\text { the cell cycle by activating cyclin-dependent kinases. }\end{array}$ & Up & $2.98 \times 10^{-4}$ & CCND1, CCNA2 \\
\hline The IGF-1 Receptor and Longevity & Down & $4.00 \times 10^{-4}$ & IGF1, PIK3R1 \\
\hline Alcoholism & Up & $4.22 \times 10^{-4}$ & $\begin{array}{l}\text { H2AFZ, HIST1H2BD, HIST1H2BH, } \\
\text { HIST1H2BK }\end{array}$ \\
\hline B Cell Survival Pathway & - & $4.57 \times 10^{-4}$ & BIRC5, PIK3R1 \\
\hline Small cell lung cancer & - & $6.12 \times 10^{-4}$ & CCND1, BCL2, PIK3R1 \\
\hline Stathmin and breast cancer resistance to antimicrotubule & Up & $6.48 \times 10^{-4}$ & CDK1, CCNB1 \\
\hline
\end{tabular}


Table II. Continued.

\begin{tabular}{|c|c|c|c|}
\hline Pathway & Regulation & P-value & Genes in the pathway \\
\hline Epstein-Barr virus infection & - & $6.64 \times 10^{-4}$ & BCL2, CDK1, PIK3R1, CCNA2 \\
\hline Skeletal muscle hypertrophy is regulated via & Down & $7.19 \times 10^{-4}$ & IGF1, PIK3R1 \\
\hline \multicolumn{4}{|l|}{ AKT/mTOR pathway } \\
\hline Rap1 signaling pathway & - & $7.54 \times 10^{-4}$ & FGF2, IGF1, PIK3R1, VEGFA \\
\hline IGF-1 Signaling Pathway & Down & $7.94 \times 10^{-4}$ & IGF1, PIK3R1 \\
\hline Ras signaling pathway & - & $1.01 \times 10^{-3}$ & FGF2, IGF1, PIK3R1, VEGFA \\
\hline $\begin{array}{l}\text { Erk and PI- } 3 \text { Kinase Are Necessary for Collagen Binding } \\
\text { in Corneal Epithelia }\end{array}$ & Down & $1.04 \times 10^{-3}$ & FYN, PIK3R1 \\
\hline Cell Cycle: G2/M Checkpoint & Up & $1.04 \times 10^{-3}$ & CDK1, CCNB1 \\
\hline Influence of Ras and Rho proteins on G1 to S Transition & - & $1.22 \times 10^{-3}$ & CCND1, PIK3R1 \\
\hline Genes related to IL4 rceptor signaling in B lymphocytes & Down & $1.32 \times 10^{-3}$ & BCL2, PIK3R1 \\
\hline $\begin{array}{l}\text { Inactivation of Gsk3 by AKT causes accumulation of } \\
\text { b-catenin in Alveolar Macrophages }\end{array}$ & Up & $1.32 \times 10^{-3}$ & CCND1, PIK3R1 \\
\hline Cholinergic synapse & Down & $1.41 \times 10^{-3}$ & BCL2, FYN, PIK3R1 \\
\hline Cell Cycle: G1/S Check Point & Up & $1.42 \times 10^{-3}$ & CCND1, CDK1 \\
\hline VEGF, Hypoxia, and Angiogenesis & - & $1.52 \times 10^{-3}$ & PIK3R1, VEGFA \\
\hline HTLV-I infection & - & $1.57 \times 10^{-3}$ & CCND1, CDC20, PIK3R1, PCNA \\
\hline $\begin{array}{l}\text { Control of skeletal myogenesis by HDAC and } \\
\text { calcium/calmodulin-dependent kinase (CaMK) }\end{array}$ & Down & $1.63 \times 10^{-3}$ & IGF1, PIK3R 1 \\
\hline Apoptosis-multiple species & - & $1.97 \times 10^{-3}$ & BIRC5, BCL2 \\
\hline How Progesterone Initiates Oocyte Membrane & Up & $2.09 \times 10^{-3}$ & CDK1, CCNB1 \\
\hline Measles & - & $2.36 \times 10^{-3}$ & CCND1, FYN, PIK3R1 \\
\hline Aldosterone-regulated sodium reabsorption & Down & $2.47 \times 10^{-3}$ & IGF1, PIK3R1 \\
\hline Apoptosis & - & $2.56 \times 10^{-3}$ & BIRC5, BCL2, PIK3R1 \\
\hline IL-2 Receptor Beta Chain in T cell Activation & Down & $2.60 \times 10^{-3}$ & BCL2, PIK3R1 \\
\hline Signaling pathways regulating pluripotency of stem cells & Down & $2.62 \times 10^{-3}$ & FGF2, IGF1, PIK3R1 \\
\hline Fluid shear stress and atherosclerosis & - & $2.78 \times 10^{-3}$ & BCL2, PIK3R1, VEGFA \\
\hline Phospholipase D signaling pathway & - & $3.01 \times 10^{-3}$ & FYN, PIK3R1, CXCL8 \\
\hline Jak-STAT signaling pathway & - & $3.63 \times 10^{-3}$ & CCND1, BCL2, PIK3R1 \\
\hline Members of the BCR signaling pathway & Down & $3.80 \times 10^{-3}$ & BCL2, PIK3R1 \\
\hline Hedgehog signaling pathway & - & $3.96 \times 10^{-3}$ & CCND1, BCL2 \\
\hline T Cell Receptor Signaling Pathway & Down & $3.96 \times 10^{-3}$ & FYN, PIK3R1 \\
\hline Endometrial cancer & - & $4.47 \times 10^{-3}$ & CCND1, PIK3R1 \\
\hline Genes encoding secreted soluble factors & - & $4.58 \times 10^{-3}$ & FGF2, IGF1, CXCL8, VEGFA \\
\hline Acute myeloid leukemia & - & $5.39 \times 10^{-3}$ & CCND1, PIK3R1 \\
\hline Non-small cell lung cancer & - & $5.97 \times 10^{-3}$ & CCND1, PIK3R1 \\
\hline VEGF signaling pathway & - & $6.18 \times 10^{-3}$ & PIK3R1, VEGFA \\
\hline Viral myocarditis & - & $6.18 \times 10^{-3}$ & CCND1, FYN \\
\hline Longevity regulating pathway-multiple species & Down & $6.80 \times 10^{-3}$ & IGF1, PIK3R1 \\
\hline Renal cell carcinoma & - & $7.45 \times 10^{-3}$ & PIK3R1, VEGFA \\
\hline Fc epsilon RI signaling pathway & - & $8.13 \times 10^{-3}$ & FYN, PIK3R1 \\
\hline Prolactin signaling pathway & - & $8.60 \times 10^{-3}$ & CCND1, PIK3R1 \\
\hline Chronic myeloid leukemia & - & $8.84 \times 10^{-3}$ & CCND1, PIK3R1 \\
\hline Longevity regulating pathway & - & $1.36 \times 10^{-2}$ & IGF1, PIK3R1 \\
\hline Genes related to Wnt-mediated signal transduction & Up & $1.36 \times 10^{-2}$ & CCND1, GAPDH \\
\hline Rheumatoid arthritis & Up & $1.39 \times 10^{-2}$ & CXCL8, VEGFA \\
\hline NF-kappa B signaling pathway & - & $1.54 \times 10^{-2}$ & BCL2, CXCL8 \\
\hline Amoebiasis & - & $1.57 \times 10^{-2}$ & PIK3R1, CXCL8 \\
\hline $\begin{array}{l}\text { Cdc } 25 \text { activates the cdc } 2 / \text { cyclin B complex to induce the } \\
\text { G2/M transition. }\end{array}$ & Up & $1.60 \times 10^{-2}$ & CDK1 \\
\hline Inflammatory mediator regulation of TRP channels & Down & $1.60 \times 10^{-2}$ & IGF1, PIK3R 1 \\
\hline
\end{tabular}



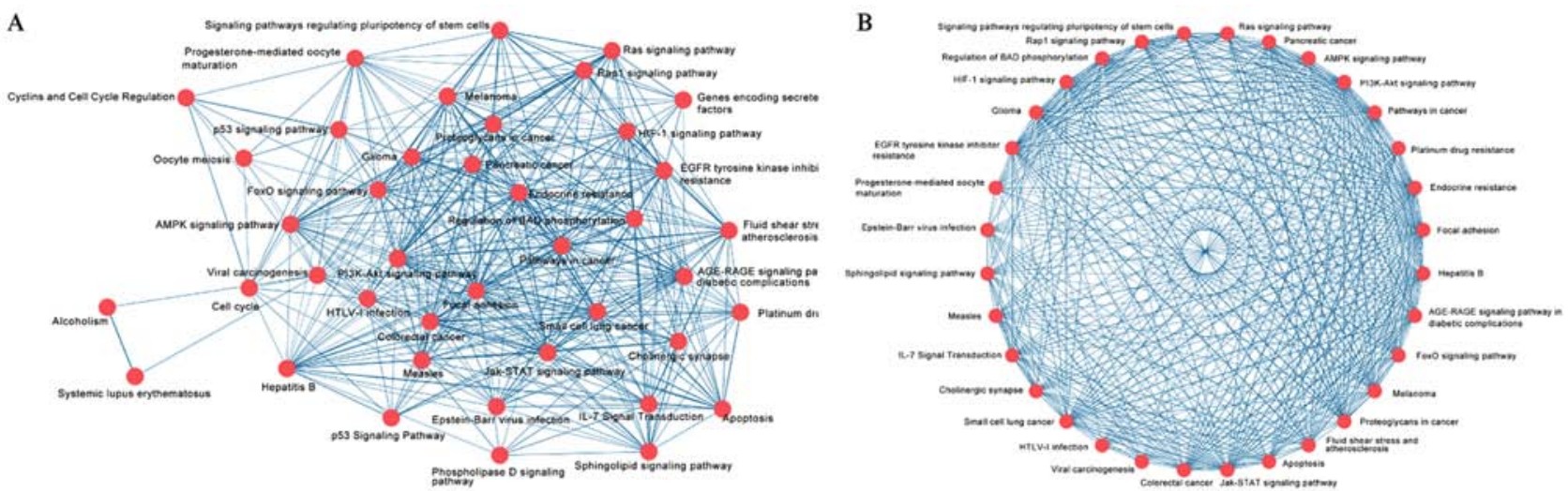

Figure 3. Pathway networks. (A) Model of the pathway network. The red circle nodes indicate a pathway and the lines represent the interactions between two pathways. The strength of the interaction is represented by the thickness of the line, according to the mean value of JC and OC. (B) Model of the core pathway network. Red circle nodes indicate a pathway and the lines represent the interactions between two pathways The strength of the interaction is represented by the thickness of the line according to the mean value of JC and OC. JC, Jaccard coefficient; OC, overlap coefficient.

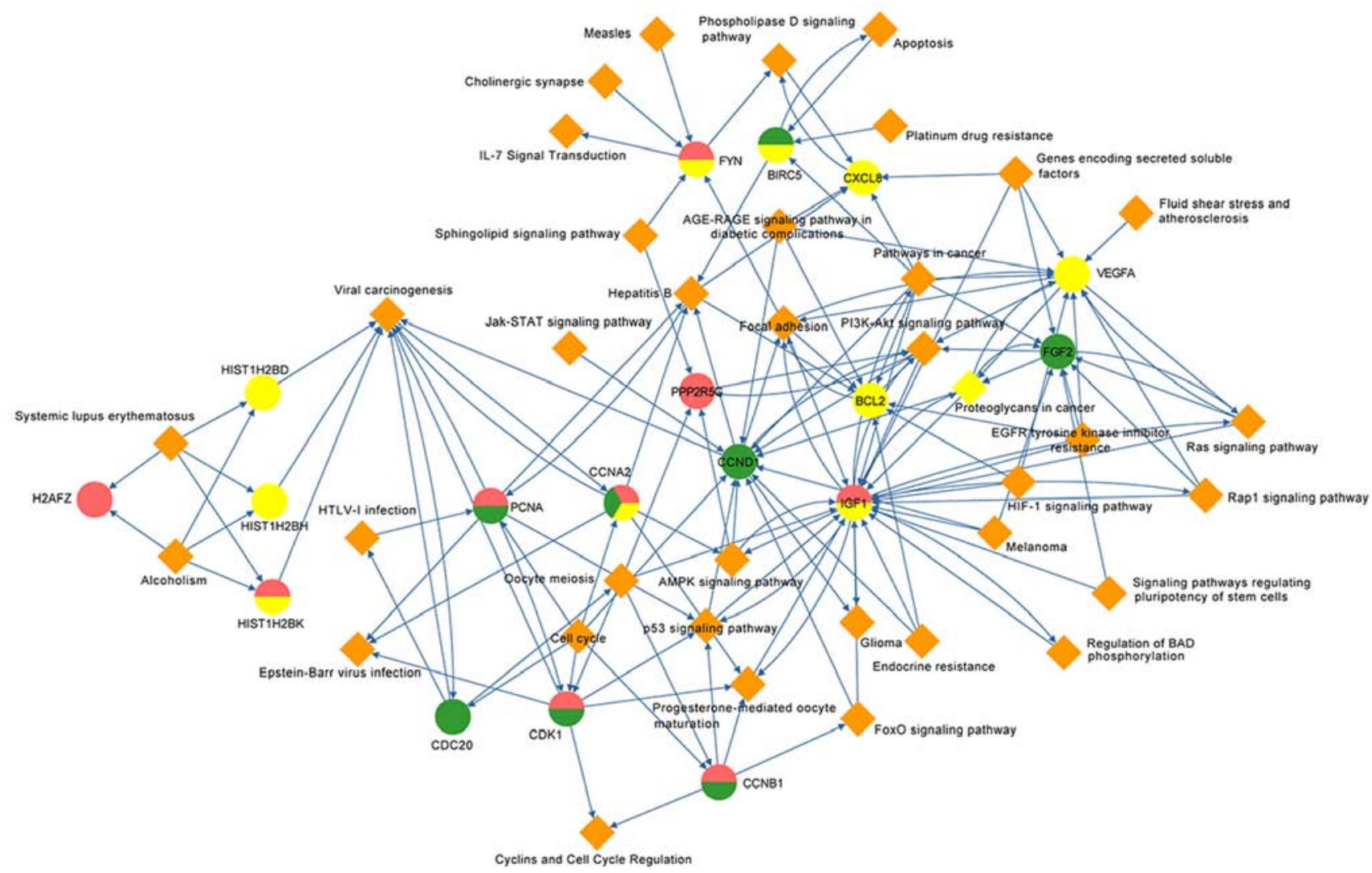

Figure 4. Gene-Pathway network. Orange diamonds indicate a pathway and circles represent a gene. Red indicates genes in cervical cancer, yellow represents genes in endometrial cancer and green indicates genes in vulvar cancer.

\section{Discussion}

In the past few decades, gynecological cancer research has developed rapidly, particularly regarding the recognition of etiological factors. Although a number of studies have investigated CC, EC and VC separately, few studies have focused on these three types of cancer in combination. The aim of the present study was to perform a systematic and comprehensive analysis to investigate the pathogenesis of $\mathrm{CC}, \mathrm{EC}$ and $\mathrm{VC}$ and make a preliminary assessment of the associations between these three cancer types.
By performing an analysis of microarray data, 1,219 DEGs were identified, including 138 in CC, 479 in EC and 734 in VC. Five DEGs were revealed in all three cancer types, which suggests these genes may participate in a number of important biological processes in gynecological cancer and may serve as crucial biomarkers following further research. Together with the 25 hub genes identified, these data may provide a direction for future research on gynecological cancer and assist with the identification of clinical biological targets.

Pathway enrichment analysis indicated that 86 pathways are closely associated with the 25 hub genes. In particular, it 


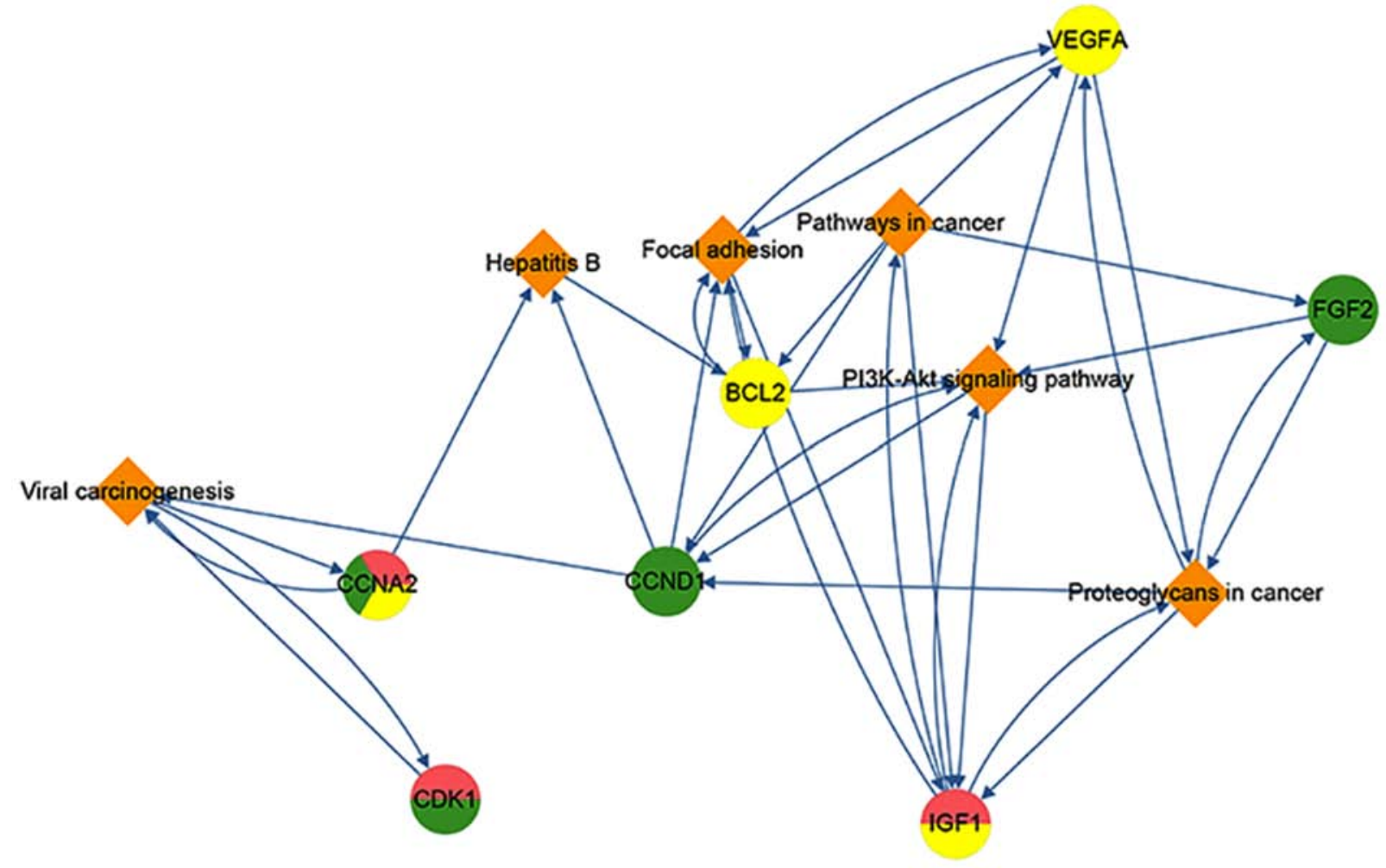

Figure 5. Sub-molecular network of CC, EC and VC. Orange diamonds indicate a pathway and circles represent a gene. Red indicates genes in CC, yellow represent genes in EC and green indicates genes in VC. CC, cervical cancer; EC, endometrial cancer; VC, vulvar cancer.

was identified that viral infection and carcinogenesis pathways were significantly enriched, including 'viral carcinogenesis', 'HTLV-1 infection' and 'hepatitis B', which supports the association of virus with the three gynecological cancer types, particularly CC. Furthermore, cancer-association pathways, including 'pathways in cancer' and 'proteoglycans in cancer' were revealed to be associated with the biological process of the three malignant tumor types. Notably, multiple different types of human cancer, including melanoma, prostate cancer, bladder cancer, breast cancer and glioma, were also identified to be associated with the 25 hub genes. This indicates that gynecological cancer types may exhibit homologous mechanisms with tumor types of other systems.

With the gene-pathway sub-network model, seven critical hub genes and six important pathways of the three gynecological cancer types were identified. The hub genes with the highest degrees included CDK1, which was enriched in $\mathrm{CC}$ and VC. As reported, CDK1 is a member of the Ser/Thr protein kinase family and is encoded by cell division cycle gene 2 (cdc2) (19). In addition, CDK1 has been revealed to serve a role in numerous types of cancer, including EC (20), breast cancer (21) and ovarian cancer (22). Consistent with the present bioinformatics results, CDK1 has been demonstrated to serve a comprehensive role in mediating genetic networks involved in the progression of CC; therefore, it may be an important therapeutic target for improving prognosis (23). A study regarding ovarian cancer identified that CDK1 is associated with proliferation and can serve as a prognostic factor in epithelial ovarian cancer (22). In EC, the overexpression of CDK1 in endometrial carcinoma cells is closely associated with the occurrence of tumors, indicating a role in tumor prognosis (24). The CDK1 gene can contribute to the carcinogenesis of HPV (25), and CC and VC are associated with HPV infection; therefore, CDK1 may be an important molecule in the pathogenesis of gynecological tumors.

Another cell cycle regulatory gene, CCNA2, was revealed as a shared DEG of CC, EC and VC, and complicated connections were identified between it and other nodes. According to recent studies, CCNA2 belongs to the highly conversed cyclin family and is expressed in multiple tissues in the human body, including numerous types of cancer, which indicates it may serve a role in cancer transformation and progression $(26,27)$. Gao et al (28) revealed that CCNA2 is a prognostic biomarker for estrogen receptor-positive breast cancer and is associated with Tamoxifen resistance. Combined with another biological analysis of EC that demonstrated CCNA2 is one of the top two upregulated nodes (29), the present study hypothesizes that CCNA2 serves a role as a biomarker in gynecological tumors (29). In addition, a study associated with ovarian cancer revealed a similar result, in which CCNA2 was upregulated in the chemo-resistant epithelial ovarian cancer (30). Therefore, it can be suggested that CCNA2 is a potential biomarker in gynecological cancer; however, this requires in vivo or in vitro experimental verification. CCND1 is an important positive regulator of the G1/S phase of the cell cycle and has been identified as a co-factor of HPV in the initiation of cervical carcinogenesis (31). Similar studies regarding EC and VC have also widely been reported (32-34).

BCL2 and IGF1 were revealed as the only two downregulated genes in the sub-network. BCL2 is an intracellular membrane protein that prevents apoptotic cell death and overexpression of BCL2 can block p53-mediated G1 arrest (35). 
Kamaraddi et al (36) demonstrated that BCL2 expression is higher in malignant lesions compared with premalignant lesions, which differs from the current findings. It has been suggested that alterations of BCL2 expression are associated with early events in cervical tumorigenesis and a lower BCL2 expression level has also been demonstrated to be associated with an improved 5-year survival rate and prognosis (37). The significance of BCL2 in gynecological tumors requires further investigation. Furthermore, IGF1 is closely associated with the occurrence of numerous tumor types; however, its exact mechanism remains unclear. Iyer et al (38) identified that IGF-1 expression levels in advanced CC increase with chemo-radiotherapy and decline during follow-up (38). With a limited specificity in gynecologic tumors, IGF1 is of limited value in the early prediction of gynecological tumors; however it may serve a role in targeted treatment strategies, and the assessment and improvement of prognosis $(39,40)$.

Angiogenesis serves an important role in tumor growth, development, progression and metastasis (41). As a pro-angiogenesis factor, VEGFA is involved in the proliferation, differentiation and migration of endothelial cells, and participates in the invasion and metastasis of numerous types of cancer (42). Chen et al (43) demonstrated that VEGFA may be a target for inhibiting angiogenesis in EC 42). Similarly, Hua and Tian (44) revealed that CCL4 can promote cell proliferation, invasion and migration of EC by targeting the VEGFA signal pathway (44). Combined with the present results, this indicates that VEGFA serves an important role in gynecological tumor invasion and metastasis.

FGF2 is a typical fibroblast growth factor that stimulates the growth of various cell types, from fibroblasts to tumor cells (45). In addition, FGF2 is a fundamental signaling molecule in tumor-induced angiogenesis (46). It has been demonstrated that FGF2 is mitogenic in various cell types and is associated with the regulation of tumor angiogenesis and metastasis (47). Certain studies regarding the receptor family of FGF2 have revealed that it is associated with the occurrence and development of CC, in addition to HPV16 infection $(48,49)$. Aberrant FGF/FGF receptor signaling has been demonstrated in multiple types of tumor $(50,51)$. The expression level of FGF2 has been revealed to be higher in EC compared with normal tissues, and the highest expression level was observed in tumors with dedifferentiation, myometrial invasion and advanced staging (52). Therefore, angiogenesis has an important impact in the pathogenesis of gynecological cancers.

'PI3K-Akt signaling pathway', 'hepatitis B', 'pathways in cancer', 'focal adhesion', 'viral carcinogenesis' and 'proteoglycans in cancer' were located in the sub-network, which indicates that these processes serve an important role in the pathogenesis of $\mathrm{CC}, \mathrm{EC}$ and VC. It is understood that the PI3K/Akt signaling pathway serves a central role in cell growth and proliferation, and it has also been suggested that its deregulation is associated with cancer (53). Yung et al (54) demonstrated that the activation of AMPK could significantly inhibit CC cell growth. Similar studies regarding the PI3K/Akt pathway in EC have also been reported $(55,56)$, and it has been considered as a therapeutic target (57). According to previous studies, the PI3K/Akt signaling pathway can serve as a therapeutic target in EC (57) and ovarian cancer $(58,59)$, and can be mediated by molecules, including VEGFA (40).
FGF2 has also been reported to serve an angiogenic role by the PI3K/Akt pathway (60). Furthermore, BCL2 is a major downstream mediator of the PI3K/Akt pathway and serves a pivotal role in tumor response $(61,62)$. It has been reported that CCNA2 expression promotes the migration, invasion and metastasis of hepatocellular carcinoma and ovarian cancer cells via the PI3K/Akt signaling pathway (63). Therefore, this crucial pathway in cancer cells may be involved in the early developmental stages of formation and invasion. As indicated by the present results, the molecular mechanisms underlying $\mathrm{CC}, \mathrm{EC}$ and $\mathrm{VC}$ are complicated, and further studies are required to fully understand their pathological mechanisms.

Similarly, Suman and Mishra (64) identified that the aurora kinase pathway has a crucial function in the pathogenesis of five gynecological cancer types, including breast cancer, EC, $\mathrm{CC}$, ovarian cancer and $\mathrm{VC}$, by analyzing the common core genes from the GSE63678, GSE57297 and GSE26712 datasets. Furthermore, the present study identified seven genes (CCNA2, CDK1, CCND1, BCL2, IGF1, FGF2 and VEGFA) and six pathways ('viral carcinogenesis', 'hepatitis B', 'focal adhesion', 'pathways in cancer', 'PI3K-Akt signaling pathway' and 'proteoglycans in cancer') that may serve an important role in CC, EC and $\mathrm{VC}$. A number of factors are involved in the progression of cancer; the present study focused on the factors associated with the female reproductive system. The results may provide comprehensive evidence that promotes the understanding of cancers of the female genital tract. While previous studies have focused on co-expressed DEGs $(23,64)$, the present study aimed to establish a gene-pathway network based on the analysis of DEGs. Additionally, previous studies investigated genes co-expressed by the five cancer types (breast cancer, EC, CC, ovarian cancer and VC). However, the current study not only investigated the co-expressed DEGs of CC, EC and $\mathrm{VC}$, but also examined the DEGs co-expressed by any combination of two of the cancer types. In summary, the current study focused of the associations between three types of tumor, which may make it more comprehensive compared with previous studies.

Notably, there are certain limitations to the present study. The sample number was relatively small, which to a certain extent reduces the credibility of gene enrichment. Subject to conditions, long-term assessments of the patients' clinical conditions were not available. In addition, the literature regarding the pathways associated with $\mathrm{CC}, \mathrm{EC}$ and EC, except for the PI3K/Akt pathway is limited; therefore, the present study lacked a solid foundation to adequately discuss the current results. Finally, certain genes that are associated with the pathogenesis of gynecological types of cancer may not have been statistically analyzed, possibly due to the exclusion criteria that was applied.

In conclusion, the pathogenesis of $\mathrm{CC}, \mathrm{EC}$ and $\mathrm{VC}$ is complicated. By performing a comprehensive analysis, the present study revealed a library of DEGs in CC, EC and VC, and identified 25 hub genes. Subsequently, viral infection, tumorigenesis, inflammation and the endocrine system were revealed to be involved in the development of these three types of cancer. Finally, a molecular network of CC, EC and VC was constructed. Most notably, it was identified that the PI3K/Akt pathway serves an important role in the three types of gynecological cancer and seven hub genes (CCNA2, CDK1, CCND1, FGF2, IGF1, BCL2 and VEGFA) present in the sub-network 
may act as therapeutic targets, and assist with early diagnosis and prevention. The present study may support the elucidation of the underlying mechanisms in $\mathrm{CC}, \mathrm{EC}$ and $\mathrm{VC}$, which would promote early detection and the development of targeted therapy. Further investigations that aim to improve understanding of the mechanisms of these three cancer types will be vital for developing highly sensitive and multifactorial strategies for the prevention, diagnosis and treatment of $\mathrm{CC}, \mathrm{VC}$ and $\mathrm{EC}$.

\section{Acknowledgements}

Not applicable.

\section{Funding}

No funding was received.

\section{Availability of data and materials}

The datasets used and/or analyzed during the present study are available from the corresponding author on reasonable request.

\section{Authors' contributions}

YL, YY and WZ conceived and designed the study. YY, WW, and KW analyzed the data. YL wrote the manuscript with contributions from all authors. All authors contributed to the interpretation of the data and writing the manuscript. The final version of the manuscript was reviewed and approved by all the authors.

\section{Ethics approval and consent to participate}

Not applicable.

\section{Patient consent for publication}

Not applicable.

\section{Competing interests}

The authors declare that they have no competing interests.

\section{References}

1. Siegel R, Naishadham D and Jemal A: Cancer statistics, 2013 CA Cancer J Clin 63: 11-30, 2013.

2. Walboomers JM, Jacobs MV, Manos MM, Bosch FX, Kummer JA, Shah KV, Snijders PJ, Peto J, Meijer CJ and Muñoz N: Human papillomavirus is a necessary cause of invasive cervical cancer worldwide. J Pathol 189: 12-19, 1999.

3. Ronco G, Dillner J, Elfström KM, Tunesi S, Snijders PJ, Arbyn M, Kitchener H, Segnan N, Gilham C, Giorgi-Rossi P, et al: Efficacy of HPV-based screening for prevention of invasive cervical cancer: Follow-up of four European randomised controlled trials Lancet 383: 524-532, 2014.

4. Castellsagué X: Natural history and epidemiology of HPV infection and cervical cancer. Gynecol Oncol 110 (3 Suppl 2): S4-S7, 2008.

5. Alkatout I, Schubert M, Garbrecht N, Weigel MT, Jonat W, Mundhenke C and Günther V: Vulvar cancer: Epidemiology, clinical presentation, and management options. Int J Womens Health 7: 305-313, 2015.

6. Bokhman JV: Two pathogenetic types of endometrial carcinoma. Gynecol Oncol 15: 10-17, 1983.
7. DiSaia PJ, Creasman WT, Mannel RS, McMeekin DS and Mutch DG: SPEC-clinical gynecologic oncology, 2017, Elsevier Health Sciences.

8. Klattig J and Englert C: The Müllerian duct: Recent insights into its development and regression. Sex Dev 1: 271-278, 2007.

9. Pappa KI, Rodolakis A, Christodoulou I, Gazouli M, Markaki S, Antsaklis A and Anagnou NP: Comparative assessment of lymph node micrometastasis in cervical, endometrial and vulvar cancer: Insights on the real time qRT-PCR approach versus immunohistochemistry, employing dual molecular markers. Biomed Res Int 2014: 187684, 2014.

10. Barrett T, Wilhite SE, Ledoux P, Evangelista C, Kim IF, Tomashevsky M, Marshall KA, Phillippy KH, Sherman PM, Holko M, et al: NCBI GEO: Archive for functional genomics data sets-update. Nucleic Acids Res 41 (Database Issue): D991-D995, 2013.

11. Ritchie ME, Phipson B, Wu D, Hu Y, Law CW, Shi W and Smyth GK: Limma powers differential expression analyses for RNA-sequencing and microarray studies. Nucleic Acids Res 43: e47, 2015.

12. Pathan M, Keerthikumar S, Ang CS, Gangoda L, Quek CY, Williamson NA, Mouradov D, Sieber OM, Simpson RJ, Salim A, et al: FunRich: An open access standalone functional enrichment and interaction network analysis tool. Proteomics 15: 2597-2601, 2015.

13. Szklarczyk D, Morris JH, Cook H, Kuhn M, Wyder S, Simonovic M, Santos A, Doncheva NT, Roth A, Bork P, et al: The STRING database in 2017: Quality-controlled protein-protein association networks, made broadly accessible. Nucleic Acids Res 45 (Database Issue): D362-D368, 2017.

14. Wang J, Duncan DT, Shi Z and Zhang B: WEB-based GEne SeT analysis toolkit (WebGestalt): Update 2013. Nucleic Acids Res 41 (Web Server Issue): W77-W83, 2013.

15. $\mathrm{Hu} \mathrm{Y,} \mathrm{Pan} \mathrm{Z,} \mathrm{Hu} \mathrm{Y,} \mathrm{Zhang} \mathrm{L} \mathrm{and} \mathrm{Wang} \mathrm{J:} \mathrm{Network} \mathrm{and}$ pathway-based analyses of genes associated with parkinson's disease. Mol Neurobiol 54: 4452-4465, 2017.

16. Franz M, Lopes CT, Huck G, Dong Y, Sumer O and Bader GD: Cytoscape.js: A graph theory library for visualisation and analysis. Bioinformatics 32: 309-311, 2016.

17. Bader GD and Hogue CW: An automated method for finding molecular complexes in large protein interaction networks. BMC Bioinformatics 4: 2, 2003.

18. Jia P, Kao CF, Kuo PH and Zhao Z: A comprehensive network and pathway analysis of candidate genes in major depressive disorder. BMC Syst Biol 5 (Suppl 3): S12, 2011.

19. Nigg EA: Mitotic kinases as regulators of cell division and its checkpoints. Nat Rev Mol Cell Biol 2: 21-32, 2001.

20. Li L, Qu YW and Li YP: Over-expression of miR-1271 inhibits endometrial cancer cells proliferation and induces cell apoptosis by targeting CDK1. Eur Rev Med Pharmacol Sci 21: 2816-2822, 2017.

21. Kang J, Sergio CM, Sutherland RL and Musgrove EA: Targeting cyclin-dependent kinase 1 (CDK1) but not CDK4/6 or CDK2 is selectively lethal to MYC-dependent human breast cancer cells. BMC Cancer 14: 32, 2014.

22. Xi Q, Huang M, Wang Y, Zhong J, Liu R, Xu G, Jiang L, Wang J, Fang $\mathrm{Z}$ and Yang S: The expression of CDK1 is associated with proliferation and can be a prognostic factor in epithelial ovarian cancer. Tumour Biol 36: 4939-4948, 2015.

23. Luo Y, Wu Y, Peng Y, Liu X, Bie J and Li S: Systematic analysis to identify a key role of CDK1 in mediating gene interaction networks in cervical cancer development. Ir J Med Sci 185: 231-239, 2016.

24. Bidus MA, Risinger JI, Chandramouli GV, Dainty LA, Litzi TJ, Berchuck A, Barrett JC and Maxwell GL: Prediction of lymph node metastasis in patients with endometrioid endometrial cancer using expression microarray. Clin Cancer Res 12: 83-88, 2006.

25. Zhang W, Liu Y, Zhao N, Chen H, Qiao L, Zhao W and Chen JJ: Role of Cdk1 in the p53-independent abrogation of the postmitotic checkpoint by human papillomavirus E6. J Virol 89: 2553-2562, 2015

26. Ruan JS, Zhou H, Yang L, Wang L, Jiang ZS and Wang SM: CCNA2 facilitates epithelial-to-mesenchymal transition via the integrin $\alpha v \beta 3$ signaling in NSCLC. Int J Clin Exp Pathol 10: 8324-8333, 2017

27. He Y, Liu J, Zhao Z and Zhao H: Bioinformatics analysis of gene expression profiles of esophageal squamous cell carcinoma. Dis Esophagus 30: 1-8, 2017.

28. Gao T, Han Y, Yu L, Ao S, Li Z and Ji J: CCNA2 is a prognostic biomarker for ER+ breast cancer and tamoxifen resistance. PLoS One 9: e91771, 2014. 
29. Zhang Y, Zhang W, Li X, Li D, Zhang X, Yin Y, Deng X and Sheng X: Prognostic factors and genes associated with endometrial cancer based on gene expression profiling by bioinformatics analysis. Arch Gynecol Obstet 293: 1287-1295, 2016.

30. Ju W, Yoo BC, Kim IJ, Kim JW, Kim SC and Lee HP: Identification of genes with differential expression in chemoresistant epithelial ovarian cancer using high-density oligonucleotide microarrays. Oncol Res 18: 47-56, 2009.

31. Catarino R, Matos A, Pinto D, Pereira D, Craveiro R, Vasconcelos A, Lopes C and Medeiros R: Increased risk of cervical cancer associated with cyclin D1 gene A870G polymorphism. Cancer Genet Cytogenet 160: 49-54, 2005.

32. Rolfe KJ, Crow JC, Benjamin E, Reid WM, Maclean AB and Perrett CW: Cyclin D1 and retinoblastoma protein in vulvar cancer and adjacent lesions. Int J Gynecol Cancer 11: 381-386, 2001.

33. Lerma E, Esteller M, Herman JG and Prat J: Alterations of the $\mathrm{p} 16 / \mathrm{Rb} /$ cyclin-D1 pathway in vulvar carcinoma, vulvar intraepithelial neoplasia, and lichen sclerosus. Hum Pathol 33: $1120-1125,2002$.

34. Moreno-Bueno G, Rodríguez-Perales S, Sánchez-Estévez C, Marcos R, Hardisson D, Cigudosa JC and Palacios J: Molecular alterations associated with cyclin d1 overexpression in endometrial cancer. Int J Cancer 110: 194-200, 2004.

35. Kurvinen K, Syrjänen K and Syrjänen S: p53 and bcl-2 proteins as prognostic markers in human papillomavirus-associated cervical lesions. J Clin Oncol 14: 2120-2130, 1996.

36. Kamaraddi S, Ashwini NU, Honnappa S and Swarup A Expression of bcl-2 marker in premalignant lesions of cervical cancer. Int J Reprod Contrac Obstet Gynecol 5: 965-969, 2016.

37. Aletra C, Ravazoula P, Scopa C, Kounelis S, Sotiropoulou G, Kourounis G, Ladopoulos I and Bonikos D: Expression of bcl-2 and bax in cervical intraepithelial neoplasia and invasive squamous cell carcinoma of the uterine cervix. Eur J Gynaecol Oncol 21: 494-498, 2000

38. Iyer P, Radhakrishnan V, Vyas R and Trivedi S: Study on the effect of chemo-radiation on the serum levels of IGF-I in patients with cancer cervix stage IIIB. Ind J Gynecol Oncol 15: 34, 2017.

39. Peyrat JP, Bonneterre J, Hecquet B, Vennin P, Louchez MM, Fournier C, Lefebvre J and Demaille A: Plasma insulin-like growth factor-1 (IGF-1) concentrations in human breast cancer. Eur J Cancer 29A: 492-497, 1993.

40. Vanamala J, Reddivari L, Radhakrishnan S and Tarver C: Resveratrol suppresses IGF-1 induced human colon cancer cell proliferation and elevates apoptosis via suppression of IGF-1R/Wnt and activation of p53 signaling pathways. BMC Cancer 10: 238, 2010.

41. Liao Y, Lu W, Che Q, Yang T, Qiu H, Zhang H, He X, Wang J, Qiu M, Zou Y, et al: SHARP1 suppresses angiogenesis of endometrial cancer by decreasing hypoxia-inducible factor-1 $\alpha$ level. PLoS One 9: e99907, 2014.

42. Baeriswyl V and Christofori G: The angiogenic switch in carcinogenesis. Semin Cancer Biol 19: 329-337, 2009.

43. Chen HX, Xu XX, Tan BZ, Zhang Z and Zhou XD: MicroRNA-29b inhibits angiogenesis by targeting VEGFA through the MAPK/ERK and PI3K/Akt signaling pathways in endometrial carcinoma. Cell Physiol Biochem 41: 933-946, 2017.

44. Hua F and Tian Y: CCL4 promotes the cell proliferation, invasion and migration of endometrial carcinoma by targeting the VEGF-A signal pathway. Int J Clin Exp Pathol 10: 11288-11299, 2017.

45. Itoh N: The Fgf families in humans, mice, and zebrafish: Their evolutional processes and roles in development, metabolism, and disease. Biol Pharm Bull 30: 1819-1825, 2007.

46. Presta M, Dell'Era P, Mitola S, Moroni E, Ronca R and Rusnati M Fibroblast growth factor/fibroblast growth factor receptor system in angiogenesis. Cytokine Growth Factor Rev 16: 159-178, 2005.
47. Folkman J and Klagsbrun M: Angiogenic factors. Science 235 442-447, 1987.

48. Cheng YM, Chou CY, Hsu YC and Chen MJ: Influence of HPV16 E6/7 on the expression of FGF2 and FGFR type B in cervical carcinogenesis. Reprod Sci 19: 580-586, 2012.

49. Cheng YM, Chou CY, Chang FM and Wing LYC: Fibroblast growth factor receptor 1 (FGFR1) overexpression play a possible role in cervical carcinogenesis: 0453. Int J Gynecol Cancer, 728, 2006.

50. Huang JK, Ma L, Song WH, Lu BY, Huang YB, Dong HM, Ma XK, Zhu ZZ and Zhou R: LncRNA-MALAT1 promotes angiogenesis of thyroid cancer by modulating tumor-associated macrophage FGF2 protein secretion. J Cell Biochem 118: 4821-4830, 2017.

51. Lee PS and Secord AA: Targeting molecular pathways in endometrial cancer: A focus on the FGFR pathway. Cancer Treat Rev 40: 507-512, 2014.

52. Fujimoto J, Hori M, Ichigo $\mathrm{S}$ and Tamaya $\mathrm{T}$ : Expressions of the fibroblast growth factor family (FGF-1, -2 and -4 ) mRNA in endometrial cancers. Tumour Biol 17: 226-233, 1996.

53. Fresno Vara JA, Casado E, de Castro J, Cejas P, Belda-Iniesta C and González-Barón M: PI3K/Akt signalling pathway and cancer. Cancer Treat Rev 30: 193-204, 2004.

54. Yung MM, Chan DW, Liu VW, Yao KM and Ngan HY: Activation of AMPK inhibits cervical cancer cell growth through AKT/FOXO3a/FOXM1 signaling cascade. BMC Cancer 13: 327, 2013.

55. Zhang Y, Goodfellow R, Li Y, Yang S, Winters CJ, Thiel KW, Leslie KK and Yang B: NEDD4 ubiquitin ligase is a putative oncogene in endometrial cancer that activates IGF-1R/PI3K/Akt signaling. Gynecol Oncol 139: 127-133, 2015.

56. Slomovitz BM and Coleman RL: The PI3K/AKT/mTOR pathway as a therapeutic target in endometrial cancer. Clin Cancer Res 18 5856-5864, 2012

57. Pavlidou A and Vlahos NF: Molecular alterations of PI3K/Akt/mTOR pathway: A therapeutic target in endometrial cancer. ScientificWorldJournal 2014: 709736, 2014.

58. Cheaib B, Auguste A and Leary A: The PI3K/Akt/mTOR pathway in ovarian cancer: Therapeutic opportunities and challenges. Chin J Cancer 34: 4-16, 2015

59. Mabuchi S, Kuroda H, Takahashi $\mathrm{R}$ and Sasano T: The PI3K/AKT/mTOR pathway as a therapeutic target in ovarian cancer. Gynecol Oncol 137: 173-179, 2015.

60. Boras EA, Matou-nasri S, Kuprinski J, Badimon L, Potempa LA and Slevin M: Abstract 181: Common angiogenic signalling pathways induced by monomeric c-reactive protein and FGF-2 through phosphatidylinositol 3-kinase. Stroke 43: A181, 2012.

61. Liu Y, Liu H, Zou J, Zhang B and Yuan Z: Dengue virus subgenomic RNA induces apoptosis through the $\mathrm{Bcl}-2$-mediated PI3k/Akt signaling pathway. Virology 448: 15-25, 2014.

62. Luna-López A, Triana-Martínez F, López-Diazguerrero NE Ventura-Gallegos JL, Gutiérrez-Ruiz MC, Damián-Matsumura P, Zentella A, Gómez-Quiroz LE and Königsberg M: Bcl-2 sustains hormetic response by inducing Nrf-2 nuclear translocation in L929 mouse fibroblasts. Free Radic Biol Med 49: 1192-1204, 2010.

63. Gopinathan L, Tan SL, Padmakumar VC, Coppola V, Tessarollo L and Kaldis P: Loss of Cdk2 and cyclin A2 impairs cell proliferation and tumorigenesis. Cancer Res 74: 3870-3879, 2014.

64. Suman S and Mishra A: Network analysis revealed aurora kinase dysregulation in five gynecological types of cancer. Oncol Lett 15: 1125-1132, 2018.

This work is licensed under a Creative Commons Attribution-NonCommercial-NoDerivatives 4.0 International (CC BY-NC-ND 4.0) License. 